УДК 82-311.6.09

Мохначева О. В.

кандидат філологічних наук, доцент

Криворізький педагогічний інститут ДВНЗ «Криворізький національний університет»

\title{
«АЛЬТЕРНАТИВНАЯ ИСТОРИЯ» КАК ФАКТОР ЖАНРОВОЙ ТРАНСФОРМАЦИИ СОВРЕМЕННОГО РОМАНА
}

У статті розглядається поняття «альтернативна історія», причини ї активізаиії в постмодерністському мистецтвві $i$ варіанти функиіонування в різних версіях сучасного роману від фантастики і міфу до біографічного і історичного допущення.

Ключові слова: «альтернативна історія», «ухронія», канонічний міф, реконструкиія історії, альтернативна біографія.

В статье рассматривается понятие «альтернативная история», причины ее активизации в постмодернистском искусстве и варианты функиионирования в различных версиях современного романа от фантастики и мифа до биографического и исторического допущения.

Ключевые слова: «альтернативная история», «ухрония», канонический миф, реконструкиия истории, альтернативная биография.

The article gives a broad outline of the notion "the alternate story», the reasons of in creasing its influence in postmodern art and a variety of its functions in different types of fiction prose ranging from fantasy and myth to biographical and historical assumption.

Keywords: "alternate story», "uchronia», canonical myth, reconstruction of history, alternate biography.

Если рассматривать современную культуру как поле напряженного творческого экспериментального поиска, нельзя не отметить особенную роль постмодернистского задания, направленного на разрушение 
устойчивых представлений о структуре и смысле мира, и следовательно, на поиск новых форм воссоздания реальности. Одной из таких востребованных форм в литературе последних десятилетий стала «альтернативная история». Реконструкция, положенная в основу этого модного в современном художественном обиходе способа обращения с фактами реальности, во многом оправдывается эстетической установкой постмодернизма. Определяя эпоху завершения парадигмы модернизма как время недоверия к «большим нарративам» (Ж. - Ф. Лиотар, «Состояние постмодерна»), разработчики постмодернизма видят основную задачу литературного произведения не в точности отражения реальности, а в создании альтернативных версий и интерпретаций, отдают предпочтение домыслу и конструированию параллельных восприятий, мистификации и литературной игре. Такой подход в первую очередь и актуализировал «альтернативную историю».

Диапазон исследовательского интереса к проблеме достаточно широк. В историко-социологическом аспекте обстоятельный обзор ее разработанности дан в статье В. А. Нехамкина «Контрфактические исторические исследования» [Нехамкин 2011]; Н. А. Ткаченко опыт альтернативной истории исследует в качестве «альтернативноисторической интенции современного мыиления» [Ткаченко 2014]; культурно-идеологический подход реализован в работе М. И. Назаренко «Альтернативная история» в советский период: генезис и динамика жанра» [Назаренко 2013] и пр., при этом специфика реализации «альтернативной истории» в разных жанровых эквивалентах в литературе все еще не прослежена исчерпывающе, что и определяет актуальность данной работы.

Цель данной статьи: исследовать диапазон функционирования «альтернативной истории» в современном романе, определить принципы использования альтернативы в различных жанровых вариантах. Задачи 
paботы: проанализировать способы реализации альтернативных версий в мифе, историческом романе, биографии и пр., обозначить художественные функции альтернативной истории.

Рассмотрение «альтернативной истории» в качестве жанровой дефиниции затруднено теоретическими разногласиями относительно жанра как литературоведческой категории в целом. Указывая на такие признаки жанра как «устойчивый тип структуры и системы образных средств» (В. Кожинов), «совокупность доминант» (Б. В. Томашевский), «конструктивный комплекс признаков: тематика, композиция, язык» (А. Цейтлин) и т.п., литературоведы приходят к выводу, что постоянных определяющих признаков жанра нет, так как в различные эпохи в одном и том же виде жанр существовать не может. Б. В. Томашевский пишет: «Жанр может быть вызван к жизни целой серией причин - бытовых, психологических, художественных, сочуиальных, каждая из которых принциипиально равноправна друг с другом. Мало того: причина, выльинувшая данный жанр, может отпасть, основные признаки жанра могут медленно изменяться, но жанр продолжает жить генетически, m. е. путем естественной ориентации, привычного примыкания вновь возникших произведений к уже сущуествующим жанрам» [Томашевский 1999:163]. Похоже, что «альтернативная история», не являясь в абсолютном смысле самостоятельным жанром, активно «примыкает» к уже существующим, оказывая на них определенное воздействие.

Изучение горизонтов «альтернативной истории» как новой дефиниции приводит к тому, что понятие углубляется и корректируется, доказательством чего служат многочисленные статьи и диссертационные работы, в которых намечены определенные подходы. Б. А. Ланин, например, указывает на опасность подмены исторической правды в «альтернативной истории»: «Переосмысливая историю, предлагая свои версии исторического прочесса развития человечества, писатели 
утверждают две вещи: человеческое знание о человеке и человечестве относительно; литературная реальность безусловно выше реальности «логически осязаемой», т.е. правда образов оказывается куда выше правды факта и правды логического умозаключения» [Ланин 2000]. Резко отрицательно оценивает альтернативную историю как порождение постмодернизма Дм. Быков: «альтернативная история - игра на понижение. Ибо в множественной, зыбкой реальности не может быть ни правых, ни виноватых... Делодаже не в том, что АИ легитимизирует псевдонаучные, лжеисторические подходы к действительности. Дело в том, что АИ отменяет реальность» [Быков 2003]. В области литературной реализации писатель делит альтернативную историю на «два равноправных потока, и разделение идет вовсе не по жанровому признаку, как можно было подумать (документальная там проза и, скажем, художественная)» [Там же], а по степени отношения к используемому историческому материалу: либо иная версия, либо перелицовка событий. Согласно концепции Быкова, причастного к созданию альтернативных романов, причины популярности этого явления - в недоверии к официальной науке и в новейших технологиях обработки сознания, нацеленных на манипуляции с восприятием.

По разные стороны дискуссии выступают многочисленные исследователи как в популярной интерпретации проблемы (например, А. Балод выделяет в альтернативно-исторической литературе различные продуктивные ответвления с элементами альтернативной истории: «криптоистория, или попросту произведения других жанров - фэнтези, детектив, мэйнстрим, пародия» [Балод 2007]); так и в более академической разработке (например, А. Зубов, исследуя альтернативную историю как модель хронотопа, ссылается на понятие «вероятности» Гомель как «силу, создающую множественность вариантов развития одного и того же «корневого» события <..> двигающего действие, 
создающего альтернативыл» и указывает на открытый финал, нерешенные загадки и уровни субъективности как на «литературные приемы, способствующие развитию сюжета лишь как одного варианта из множества равнозначных вероятностей» [Балод 2007] или А. Б. Бочаров, который изучает альтернативную историю в контексте естественнонаучной парадигмы [Бочаров 2005]). Н. П. Дворцова называет «альтернативную историю» жанром, связывая еe с антиутопией, создающей альтернативные модели культуры в традиции апокрифического мышления, и пытается вывести «парадигму литературы возможных альтернатив», указывая в качестве ее признаков на «эксперимент со временем, языком, авторством» и включение «сакрального текста на фоне альтернативной истории» [Дворцова 2003].

Как видим, этот далеко не исчерпывающий обзор научной истории проблемы отличается широким диапазоном подходов не только к определению самого понятия «альтернативной истории», но и к пониманию функционирования подобного способа организации текста, его художественного задания и классификации. В развернутой и хорошо аргументированной критико-библиографической книге С. Соболева «Альтернативная история: пособие для хронохичхайкеров» предпринята попытка сопоставить различные трактовки в понимании этой литературы, классифицировать произведения в жанре альтернативной истории, развести их с криптоисторическими романами и проследить основные этапы формирования. Основное внимание исследователя сосредоточено на фантастике, тем не менее, им сделано такое существенное наблюдение: «Предтечи жанра АИ надо искать в частной истории, story, а не в общей истории, history» [Соболев 2006:17].

Сделанное замечание объясняет, почему эта модная художественная модель нашла такое широкое распространение в романе эпохи постмодернизма: используя разные жанровые модификации, 
«альтернативная история» сама становится «точкой бифуркации», механизмом, при помощи которого современный текст перестраивается, расширяет границы, приобретает такие качества, как нелинейность, многоуровневость, интертекстуальность, ризоморфность и пр.

В сочетании с разными жанровыми вариантами «альтернативная история» проявляет устойчивые признаки. В. И. Демин, исследуя трансформацию мифа и его роль в историческом романе, считает причиной его активного «переписывания» сомнение в объективности истории: «Необходимость в пересмотре истории становится причиной «деформации» исторического романа, возникновения множества научнопопулярных текстов, интерпретирующих ее, и новых литературных жанров - одним из них становится жанр «альтернативной истории», «ухронии» [Демин 2012]. Оправдывая постмодернистскую версию исторических событий как альтернативную и неофициальную, автор признает за ней право на переписывание общепринятой версии «с позищ̧ией безмолвного «меньиинства», что имеет значение для опосредованного, личностного восприятия излагаемых (или интерпретируемых) событий.

В научном обиходе в смысле жанрового новообразования «альтернативной историей» обычно называют разновидность фантастической литературы, которая моделирует различные версии как реальных, так и вероятных событий. Она представлена такими ведущими модераторами жанра, как Роджер Желязны, Анджей Сапковский, Филипп К. Дик, Джаспер Форде, Стивен Кинг и др.

«Альтернативная история» как разновидность фантастической литературы существует в статусе жанра, изображающего вариативную реальность, возможную в том случае, когда историяв один из своих переломных моментов (точек бифуркации или точек развилки) развивается по другому пути. Образцом такой истории являются, например, иноверсия исхода Второй мировой войны в романе «Человек в высоком замке» 
Ф. Дика, версия убийства президента Кеннеди «11/22/63» С. Кинга, «Остров Крым» В. Аксенова, романы трилогии «О» Дм. Быкова о судьбах русской революции и др.

Другим устойчивым вариантом альтернативной истории в фантастике является интерпретация канонического мифа: иноверсия мифа о Беовульфе в постмодернистской фантазии «Грендель» Д. Гарднера, «Троя» Д. Геммела, «Битва титанов» А. Д. Фостера и пр. Миф особенно часто используется как основа для «альтернативной истории», так как заложенный в нем информационный архетип дает широкие возможности для интерпретации.

В каком-то смысле «альтернативной историей» можно назвать и такие нефантастические по определению романы, как «Доктор Фаустус» Т. Манна, «Орикс и Коростель» М. Этвуд, «Медея» К. Вольф, «Евангелие от Иисуса» - трактовку Нового Завета лауреата Нобелевской премии по литературе 1998 года португальца Жозе Сарамаго. Используя миф как основу сюжета, подобные романы не сосредоточены на его переписывании, но воссоздают интерпретацию оценивания, переосмысления канона по принципу постмодернистского отказа от «реальности наизусть» (Т. Адорно), при этом сохраняя статус либо интеллектуального романа, либо ретроспективной прозы, либо историзованного мифа.

В украинской версии особенности «альтернативной истории», выстроенной на основе мифа, хорошо видны в творчестве двух харьковских авторов, успешно работающих под псевдонимом Генри Лайон Олди. Они интерпретировали древнеиндийский эпос «Махабхарата» в трилогии «Черный Баламут», серию различных мифов в романах «Мессия очищает диск», «Одиссей, сын Лаэрта» и др.

В романе «Герой должен быть один» (1995) пересказан миф о Геракле и его подвигах. В своей основе он соответствует ключевым 
моментам канона, однако альтернативная версия заметно отходит от задач древнего мифа. Показательно, что сами авторы дают установку читательскому восприятию, начиная вторую часть книги «Жрецы» эпиграфом известного исследователя мифа Я. Голосовкера: «Но как объяснить кровавость, жестокость и трагизм мифов у такого жизнерадостного народа, как древние эллины? Как ни передельвались позднее мифы поклонниками Олимпийского пантеона - кровавые ужасы их сюжета были уже канонизированыл». Битва титанов, богов и героев в интерпретации Олди приобретает современное звучание: анализ поступков героев связывается с новым пониманием причин противоборства Олимпийской Семьи и свергнутых в Тартар титанов; люди иллюстрируют своим участием или гибелью некие бытийные смыслы, обусловленные постижением законов, проявляющихся с течением неумолимого времени; приступы безумия Геракла, цементирующие миф, имеют убедительное объяснение, роль брата-близнеца трактуется с двух разных позиций и т.д. Такое построение текста совпадает с рассуждением, подводящим своеобразный, промежуточный итог альтернативной истории Геракла в финале первой книги «Жертвы»: «Bот что осталось от двадиати трех лет жизни Геракла спустя всего тысячу лет; а то, что останется через три с половиной тысячелетия, будет достойно лишь служить погремушкой в руках великовозрастных детей! O мудрые pancoды! Ничтоже сумняшеся, они будут повторять друг за другом, как Геракл загнал неуязвимого Немейского льва в пещчеру с двумя выходами, один из которых завалил камнями, после чего вошел во второй и удушил чудовище - и никто не задумается, почему лев не покинул логово череззапасной выход, пока герой таскал камни к первому?! <..> Слеп был Гомер; дважды слепцุами будут преемники Гомера» [Двоцова 2003].

Как видим, задача альтернативного варианта мифа в данном случае не просто пересказать древний сюжет в каноническом виде, но и 
исследовать логику событий, вскрыть механизм судьбы Геракла, особенности его личной истории, «просветить» схему мифа эмоциями, живым человеческим чувством и заставить его ожить, сохранив в адаптированном для современного восприятия виде.

В другом ключе «альтернативная история» работает в романе английской писательницы Сюзанны Кларк «Джонатан Стрендж и мистер Норрелл» (2004). Хотя в основу этого виртуозного текста положен не миф, а история Англии периода Наполеоновских войн, реальность здесь только повод для создания в рамках исторического пастиша альтернативного мира магии и приземленного английского бытописательства, прием, который сама Кларк назвала «заземлением магии». Подобным же образом воссоздан и мир альтернативной Америки в книге О. С. Карда «Седьмой сын» (1987), которую остроумный комментатор назвал игрой на тему: «Найди все намеки на историю Америки, которая была в реальности». Наполеон, Бенджамин Франклин в роли волшебника, Джордж Вашингтон, поэт Уильям Блейк - такой набор персонажей делает историю книги не просто альтернативной, но даже провокационной, так как события нелегко соотнести с теми, что были на самом деле. В этом случае альтернативная версия, скорее всего, активизирует познавательную функцию читателя. Демонстративные несоответствия с историческими событиями отсылают к определению жанра ухронии - «утопической реконструкиии истории, причем не такой, какая была на самом деле, а той, которая могла бы быть. Термин создан в 1876 г. Ренувъе в рамках его теории, представляющей Европу, какой она могла стать, если бы Наполеон выцграл битву при Ватерлоо. Понятие ухронии предполагает случайный характер исторических событий» [Жюлиа 2000:502].

Распространенной версией альтернативы в эпоху постмодернизма стал вариант дописывания (или переписывания) биографии известных 
личностей, исторических деятелей или писателей. Принцип «художественного вымысла, не отягощенного биографической скрупулезностью», как обозначил свой подход Ж. Эшноз, привел к варианту альтернативной истории: в его романе «Молнии» (2010), задуманном как биография Николы Теслы, автор в итоге настолько далеко отошел от биографической канвы, что вынужден был дать персонажу другое имя. Роман Д. Ногеза «Три Рембо» (1986), дорисовывающий долгую жизнь знаменитого поэта с момента его смерти, подчеркнуто классифицирован как «альтернативная биография». Причины такого активного «переписывания» в случае с Рембо объясняет критик: «Жизнь Артюра Рембо и две его смерти - смерть поэта в двадияатилетнем возрасте и физическая смерть в 37 лет - породили множество легенд и предположений. Загадка Рембо, над которой трудятся многочисленные интерпретаторы, связана с его уходом от поэзии. Путь, по которому исследователи творчества поэта предлагают пойти - «это зазор между созданными им текстами и его биографией, то есть между «жизнью»и «литературой» [Свободная 2007]. Продлив гипотетическую жизнь Рембо в альтернативной биографии, Д. Ногез демифологизировал личность поэта, исследовал последствия и психологические риски его детских травм, нанесенных жестокой матерью, бывшей согласно официальной биографической концепции причиной бунта и гнева этого «чудо-ребенка».

Не менее виртуозным и неожиданным вариантом альтернативной биографии стал роман именитого писателя, нобелевского лауреата Дж. М. Кутзее «Осень в Петербурге» (1994). Герой романа Ф. М. Достоевский в 1869 году тайно приезжает из-за границы в Петербург, узнав о самоубийстве своего юного пасынка Исаева. Персонажами истории становятся реальные лица, пересекавшиеся с писателем в его жизни, а также герои его романов, обретающих реальность по воле писателя, причины самоубийства молодого человека 
анализируются с различных сторон, в частности, и как результат анархической деятельности Павла. И только в финале романа Кутзее дописывает фразу: «Оm переводчика: Павел Александрович Исаев скончался в 1900 г. в возрасте пятидесяти четырех лет», разрушая эффект правдоподобия и обнаруживая элементы реконструкции событий в альтернативном варианте.

Как видим, «альтернативная история» - это вместительное обозначение для современных подходов к интерпретации событий в ключе фантастического допущения, пересказа мифа, невероятных иноверсий о том, как могла бы повернуться история в своем ключевом повороте, попыток воссоздать или дописать эпизоды судеб известных исторических или же культурных деятелей. Попытки выделить «парадигму литературы возможных альтернатив» [Дворцова 2003] сводятся в основном к характеристикам хронотопа, ключевой поворотной «точке бифуркации», переносе внимания с «человека в истории» на осмыслении уроков истории человеком. В некотором смысле, «альтернативная история» находится в русле постмодернистского экспериментав сфере сознания: это художественно заданная игра в условности, в варианты, отказ от цементирования концепций общей истории за счет историй частных, и более того, манипуляция с пространством текста.

Обозначившись в пределах фантастической парадигмы, «альтернативная история» сохраняет присущую этому способу моделирования действительности вариабельность форм, установку на альтернативность будущего и неоднозначность путей эволюции, моделирует события в исторической ретроспекции. Приемы, используемые в литературе подобного рода - реконструкция, реверс, ретропрогнозирование, выстраиваются по нескольким структурным моделям. В некоторых случаях положенные в основу произведения реальные факты историисохраняются как ключевые эпизоды и 
дорисовываются за счет развернутого комментария (X. Мантелл «Вулфхолл»); в других альтернатива работает как категория возможного против устойчивого ритуала (переписывание мифов); в третьих служит поводом для переоценки событий, иногда даже в форме пародии или насмешки (Хольмван Зайчик). Существуя в формах реконструктивного или реверсивного «квазипредвидения» (И. В. Бестужев-Лада) в текстах, ориентированных на фантастическое или альтернативное переосмысление реальности, эта литературная программа широко использует хронотоп «исторического перекрестка» с целью совмещения линейных и циклических характеристик времени.

\section{БИБЛИОГРАФИЯ}

Балод: 2007 - Балод А. Десять парадоксов альтернативноисторической литературы / А. Балод. - Режим доступа: http://zhurnal.lib.ru/ b/balod_a/12.sh

Бочаров 2005 - Бочаров А.Б. Альтернативная история в контексте естественнонаучной парадигмы: версия системного анализа // Фигуры истории, или «общие места» историографии. Вторые санкт-петербургские чтения по теории, методологии и философии истории. - СПб. : Северная звезда, 2005. - С. 7-18.

Быков 2003 - Быков Д. Другой альтернативы у нас есть! (альтернативная фантастика как наше всё) // Д. Быков. Вместо жизни: очерки, заметки, эссе. - Режим доступа: http://www.google.ru/url?sa=t\&rct= $\mathrm{j} \& \mathrm{q}=\& \operatorname{esrc}$

Демин 2012 - Демин В. И. Исторический миф и миф об истории в современном постмодернистском романе : автореф. дисс... к. филол. н.M., 2012. - 267 с. - Режим доступа: http://www.dissercat.com/content/ istoricheskii-mif-i-mif-ob-istorii-v-sovremennom-postmodernistskom-romane 
Дворцова 2003 - Дворцова Н.П. Миф о смерти постмодернизма и современная литературная ситуация. - 03/07/2003 - Режим доступа: http://www.topos.ru/article/1338

Жюлиа 2000 - Жюлиа Д. Философский словарь [Пер. с франц.] / - М. Междунар. Отношения, 2000. - 544 с.

Зубов 2012 - Зубов А. «Топографический поворот»: исследования о времени и пространстве в спекулятивной фантастике // «НЛО». - 2012. № 113. - Режим доступа: http://magazines.russ.ru/nlo/2012/113/z42-pr.html

Ланин 2000 - Ланин Б.А. Трансформации истории в современной литературе // Общественные науки и современность. - 2000. - № 5. Режим доступа: http://ons.gfhs.net/2000/5/17.htm

Назаренко 2013 - Назаренко М.И. «Альтернативная история» в советский период : генезис и динамика жанра. - Режим доступа: irbisnbuv.gov.ua/cgi-bin/.../cgiirbis_64.exe

Нехамкин 2011 - Нехамкин В. А. Контрфактические исторические исследования // Историческая психология и социология истории. Том 4. - № 1. - 2011. - Режим доступа: http://www.socionauki.ru/journal/ articles/134125/

Свободная 2007 - Свободная О. Судьба Артюра Рембо: варианты интерпретации. - 02.04.2007. - Режим доступа: http://www.proza.ru/2008/05/ 10

Соболев 2006 - Соболев С. Альтернативная история: пособие для хронохичхайкеров / С. Соболев. - Липецк : «Крот», 2006. - 84 с.

Ткаченко 2014 - Ткаченко Н. А. История в сослагательном наклонении: опыт альтернативной истории // Ученые записки Таврического національного университетаим. В.И. Вернадского. - Серия «Философия. Культурология. Политология. Социология». - Том 27 (66). 2014. - № 1-2. - С. 167-174.

Томашевский - Томашевский Б. В. Теория литературы. Поэтика : учеб. пособие : [изд. 2-е; Вступ. статья Н. Д. Тамарченко] / Б. В. Томашевский. - М. : Аспект Пресс, 1999. - 334с. 